\title{
Impairment Induction by Axotomy in Motor Functional and Histological Anterior Horn of Spinal Cord Structure
}

\author{
Inducción del Deterioro por Axotomía en la Estructura Motora \\ Funcional e Histológica del Asta Anterior de la Médula Espinal
}

Amir Raoofi ${ }^{1}$; Saeed Gharibian ${ }^{2}$ \& Yousef Sadeghi ${ }^{3}$

RAOOFI, A.; GHARIBIAN, S. \& SADEGHI, Y. Impairment induction by axotomy in motor functional and histological anterior horn of spinal cord structure. Int. J. Morphol., 37(3):1101-1106, 2019.

SUMMARY: We have surveyed the motor changes in rats subjected to sciatic nerve axotomy. The rats were divided into two groups, each one consisting of ten animals, which underwent the following intervention: The first group (control): healthy rats without any injuries and experimental group: rats with injured sciatic nerve without treatment. at 12 weeks, the L4 and L5 spinal cord segments were removed. We evaluated nerve function using muscle electromyography (EMG) activity and sciatic function index (SFI) simultaneously with histological spinal cord analyses by stereological methods at 12 week. After nerve injury presented gross locomotor deficits at week 12 . We also found that the volume of the anterior horn of spinal cord and total number of motor neurons were decreased after nerve axotomy $(\mathrm{p}<0.05)$. In conjunction, these results indicate that peripheral nerve injuries have more severe consequences on hind limb motor output.

KEY WORDS: Degenerative; Anterior horn of spinal cord; Stereology; Axotomy; Motor functional.

\section{INTRODUCTION}

Axotomy of Peripheral Nerve Injury (PNI), caused by trauma and medical disorders (Grinsell \& Keating, 2014). Severe nerve injury has a devastating impact on a patients' quality of life. Typical symptoms are sensory and motor function defects that can result in complete paralysis of the affected limb or development of intractable neuropathic pain (Siemionow \& Brzezicki, 2009). Most of the peripheral nerves, especially spinal nerves, are mixed nerves which contain motor nerve fibers and sensory nerve fibers (Park et al., 2008; Frade \& Ovejero-Benito, 2015). Following peripheral Axotomy, some the dorsal root ganglion(DRG) and ventral horn neurons undergo a series of retrograde degenerative changes classic that lead to neuronal death (Himes \& Tessler, 1989; Vestergaard et al., 1997; Terenghi, 1999; Pierucci \& de Oliveira, 2006). The degenerative changes of neurons are made by damage-induced interruption of the flow of neurotrophic factors from perimeter, to neuronal body by retrograde transport (Terenghi, 1999).
Albeit Three different type of graft including autografts, allografts, and xenografts have been used for nerve regeneration, they possess the disadvantages Consist of immunological rejection and finite availability (Zalewski \& Gulati, 1981; Hyun \& Kim, 2010). Previous studies have shown that motoneuron degeneration in the spinal cord following injury is mediated by apoptosis evolved in association with oxidative stress, possible due to trophic factor deprivation, as well as by activation of death receptors (Wiberg et al., 2017). As for PNI, motor functional recovery is one of most important aspects for the patients, while the recovery depends on axonal regeneration from the motoneurons (Park et al.; Frade \& Ovejero-Benito). The functional repair is far from the expected level which mainly due to the axonal regenerative rate is quite slow (Wood et al., 2011). Therefore, we hypothesized that axotomy induced impairment in motor functional and histological structure of anterior horn of spinal cord.

\footnotetext{
${ }^{1}$ Department of Anatomical Sciences, School of Medicine, Sabzevar University of Medical Sciences, Sabzevar, Iran.

${ }^{2}$ Student Research Committee, Dentistry Research Center, Research Institute of Dental Sciences, Dental School, Shahid Behesti University of Medical Sciences, Tehran, Iran.

${ }^{3}$ Department of Biology and Anatomical Sciences, School of Medicine, Shahid Beheshti University of Medical Sciences, Tehran, Iran.
} 


\section{MATERIAL AND METHOD}

Animals and surgical procedures. Twenty adult male wistar rats that weighed approximately $260 \mathrm{~g}$ were used and Rats were housed individually in standard rat in cages $20 \times 20 \times 40$ $\mathrm{cm}$ in size in a standard animal home (12-h light/12-h dark environment), and provided with water ad libitum. rats were randomized into two groups $(n=10)$ : (1) Normal group: healthy rats without any injuries, (2) Axotomy group: rats with injured sciatic nerve without treatment.

Briefly, animals were anesthetized by intraperitoneal injection of sodium pentobarbital ( $40 \mathrm{mg} / \mathrm{kg}$ body weight) before the sciatic nerve was exposed by making a $2 \mathrm{~cm}$ longitudinal skin incision then interrupted in the position $0.5 \mathrm{~cm}$ below ischial tuberosity in the right lateral thigh. the nerve segment $(10 \mathrm{~mm})$ was removed. After surgery, animals in all groups were housed in their cages and fed routinely under normal conditions.

Sciatic Function Index (SFI). 4, 8 and 12 weeks post surgery, the walking pattern of animals were recorded for the analysis of the sciatic functional index (SFI) as described previously. Briefly, the rats were trained a few preexperiment to walk down a wooden track $(100 \times 20 \times 15 \mathrm{~cm})$ into a darkened goal box. After surgery, the animal's hind paws were dipped using inkpad and the changes in their paw prints that resulted from nerve lesion and denervation were recorded. The recordings continued until five measurable footprints were collected. From the footprints, the following parameters were calculated using a ruler: print length (PL) that refers to the distance from the heel to the top of the third toe, intermediary toe spread(ITS) that refers to distance from the second to the fourth toe and toe spread (TS) the distance between the first and the fifth toe. All these measurements were obtained both from the right experimental foot (EPL, ETS and EITS, respectively) and from the left non- operated foot (NPL, NTS and NITS, respectively) of each rat. By using these data, SFI was calculated by the following equation (Bain et al., 1989).

$\mathrm{SFI}=-38.3($ EPL- NPL $) / \mathrm{NPL}+109.5(\mathrm{ETS}-\mathrm{NTS}) / \mathrm{NTS}$ $+13.3($ EIT- NIT) $/$ NIT -8.8

SFI value of nearly 0 represents normal, while an SFI value of -100 indicates total dysfunction of the sciatic nerve

Electromyographic studies (EMG). Following 12 week of nerve scaffold implantation, EMG evaluation was performed on all rats prior to sacrifice. Under intraperitoneally xylazine $(8 \mathrm{mg} / \mathrm{k})$ and ketamine hydrochloride $(60 \mathrm{mg} / \mathrm{kg})$ anesthesia, the right sciatic nerve of the operated side was re-exposed by longitudinal incision on the posterior aspect of each thigh from the greater trochanter to the knee. A bipolar stimulating electrode was positioned to the nerve trunk at at a location $10 \mathrm{~mm}$ proximal to the site of the repair and compound muscle action potentials (CMAPs) were recorded in the belly of the gastrocnemius muscle at the ipsilateral side using an EMG recorder. The physiologic parameters including the peak amplitude of compound action potentials and latency were measured (Ahmadi et al., 2018).

Perfusion and tissue collection. After 12 weeks, animals were anesthetized with ketamine $(100 \mathrm{mg} / \mathrm{kg})$ and xylazine $(10 \mathrm{mg} / \mathrm{kg}$ ) intraperitoneally, then rats were perfused intracardially with $150 \mathrm{ml}$ normal saline and $200 \mathrm{ml} 4 \%$ paraformaldehyde (PFA). Spinal cord samples were extracted and post-fixed in $4 \%$ paraformaldehyde at 48 ${ }^{\circ} \mathrm{C}$ for 4-5 days. The paraffin blocks were prepared and were cut in serial sections of $10 \mu \mathrm{m}$ thickness, which were stained with cresyl violet.

Cresyl violet staining of spinal cord. Transverse sections were re-hydrated in $70 \%, 95 \%, 95 \%, 100 \%$, and $100 \%$ ethanol ( 3 min each). After a $1 \mathrm{~min}$ wash in water, the slides were incubated in $0.25 \%$ cresyl violet in $200 \mathrm{mM}$ acetate buffer for $30 \mathrm{~min}$. Following 10 dips each in water, $70 \%$ and $100 \%$ ethanol, the tissue was differentiated in $0.25 \%$ glacial acetic acid until white matter was visible. Then the slides were dipped in $95 \%$ and $100 \%$ ethanol (10 dips each), and cover-slipped using Permount (Fisher Scientific, Unionville, Canada). were. slides viewed by light microscope (Nikon, Japan).

Motoneurons were identified by their position in the spinal cord (ventral horn, lamina IX), size (substantially larger than interneurons and glial cells), and presence of Nissl substance arranged in polygonal clumps. The motoneurons present in the ventral horn on the ipsilateral and contralateral sides to the injury were counted in alternate sections of each specimen in the injured area of the lumbar intumescence. Only cells with visible nuclei were counted.

Stereological estimate of the total volume of anterior horn of spinal cord. The volume was estimated using the Cavalieri method. briefly, 10 sections are selected using systematic, uniformly random sampling (SURS) for stereological estimations. Each microscopic slide was analyzed using a video microscopy system which was made up of a microscope (E-200, Nikon, Tokyo, Japan) linked to a video camera, a computer, a flat monitor, and a microcator (MT-12, Heidenhain, Traunreut, Germany). The formula for calculation of volume of anterior horn of spinal cord was as follows (Noorafshan et al., 2014) (Fig. 1): 


$$
\mathrm{V}_{\text {spinal anterior horn }}=\sum \mathrm{P} \times \mathrm{d} \times \frac{\mathrm{a}}{\mathrm{p}}
$$

where " $\Sigma \mathrm{P}$ " was the total points hitting the anterior horn of spinal cord sections, "a/p" was the area associated with each point, and "d" was the distance between the sampled sections.

Stereological Estimate of the Number of neurons. The optical dissector method was used to determine the total number of neurons. Random sampling was ensured by moving the microscopic field position at equal intervals. A microcator was used for measurement of the Z-axis movement of the microscope stage. An unbiased counting frame, with exclusion and inclusion margins, was superimposed, according to the sectional images, which were observed on the monitor. A nucleus was counted if it fell completely or
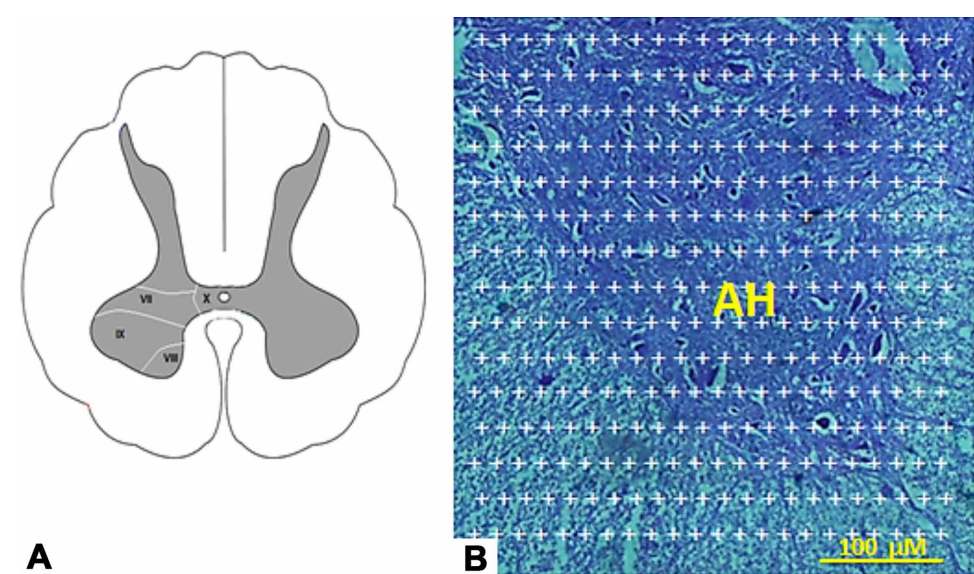

A partially within the counting frame, and did not reach the exclusion line. The formula for calculation of numerical density (Nv) was as follows (Noorafshan et al.) (Fig. 2):

$$
\mathrm{N}_{\mathrm{v}}=\frac{\sum \mathrm{Q}}{\sum \mathrm{P} \times \mathrm{h} \times \frac{\mathrm{a}}{\mathrm{f}}} \times \frac{\mathrm{t}}{\mathrm{BA}}
$$

where SQ is the number of the nuclei, $h$ is the height of the disector, $a / f$ is the frame area, SP is the total number of the unbiased counting frame in all fields, $t$ is the real section thickness measured in every field using the microcator, and BA is the block advance of the microtome which was set at $10 \mathrm{~mm}$. The total number of the neurons was estimated by multiplying the numerical density $(\mathrm{Nv})$ by the total $\mathrm{V}$.

$$
\mathrm{N}_{\text {total }}=\mathrm{N}_{\mathrm{v}} \times \mathrm{V}
$$

Data Analysis. Comparison between groups was made by one-way analysis of variance (ANOVA) followed by Tukey's multiple comparison test to analyze the difference. Walk data were analyzed using the two-way ANOVA method (repeated measures mixed model ANOVA). After two-way ANOVA, differences between curves/groups were determined by the Mann-Whitney test. All statistical work was performed in IBM SPSS version 21. All data are represented as the mean \pm SEM. The significance of the comparisons was set at $\mathrm{p}<0.05$.

Fig. 1. Volume study. A and B. Schematic drawings of transverse section from L5 level of the spinal cord in control and axotomy groups. Photomicrograph of the spinal cord stained with Cresyl violet (10x). A grid of points was superimposed on the Image for estimation of total volume of anterior horn of spinal cord. Anterior horn of spinal cord (AH).
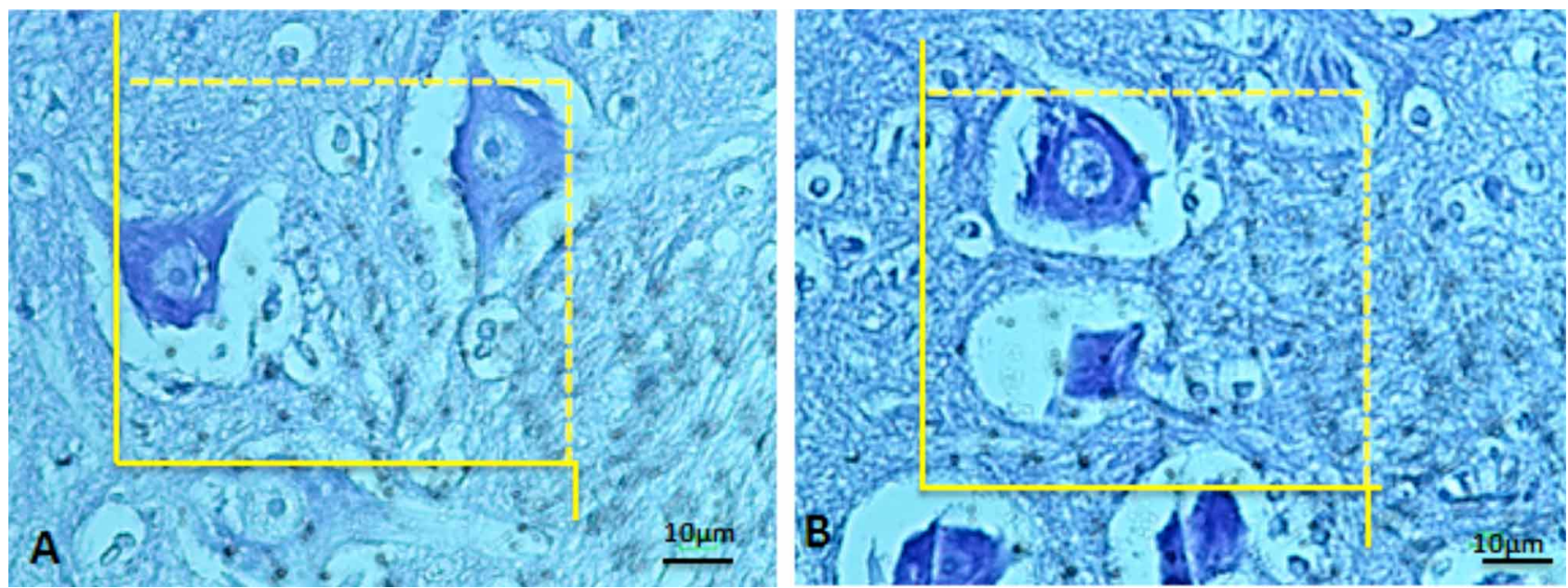

Fig. 2. Number study. Photomicrographs of the spinal cord stained with cresyl violet staining (40x). Counting frames were superimposed on images for estimation of total number of anterior horn of spinal cord neurons. A. Control. B. Axotomy group. 


\section{RESULTS}

Walking track analysis was performed to assess the recovery of locomotive function in the rats.

At weeks 4,8 and 12 , Rats in the axotomy groups showed time-dependent decreases in SFI values due of sciatic nerve degeneration and gastrocnemius muscle atrophy that were significantly different compared to control group $(\mathrm{P}<0.001)$ (Fig. 3).

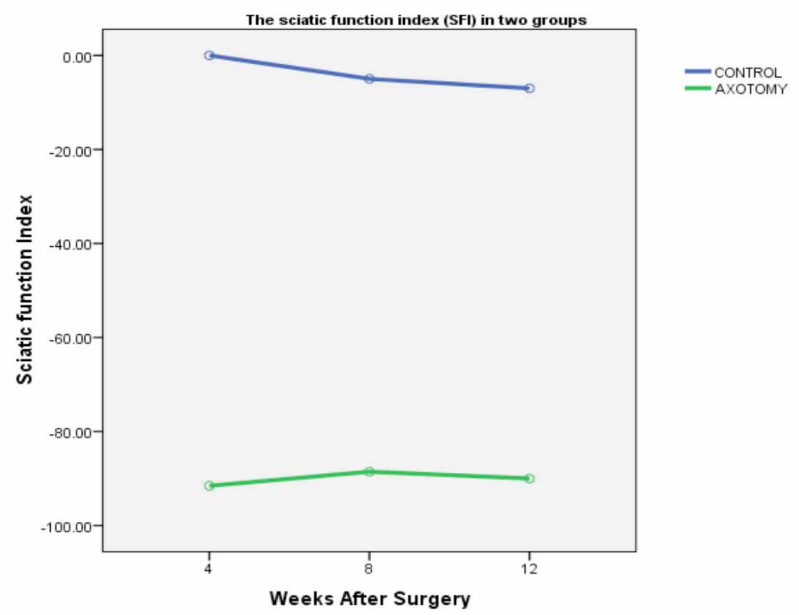

Fig. 3. The sciatic function index (SFI) in all groups. The significant difference between axotomy group with the control group is indicated. $* * * \mathrm{p}<0.001$.

Muscle EMG Activity. At week 12 post operation, results showed that compound action potential amplitude in gastrocnemius muscle was reduced in axotomy group compared with that in control. Difference was statistically significant $(\mathrm{p}<0.001)$. Significant differences in the latency after sciatic nerve injury were seen between the 2 groups $(\mathrm{p}<0.001)$ (Fig. 4; Table I).

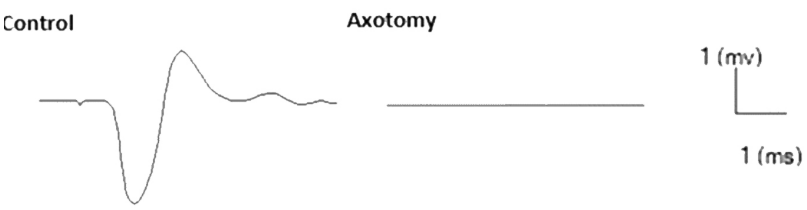

Fig. 4. Muscle activity in rats. The sciatic nerve was stimulated, and the muscle action potential and latency were recorded in the gastrocnemius muscle.

Table I. Comparison of Amplitude and Latency in each group at week 12 postoperation All data were expressed as the mean \pm standard error of mean.

\begin{tabular}{llcc}
\hline Groups & Control & Axotomy & $\mathrm{P}$ value \\
\hline Amplitude(mv) & $34.03 \pm 1.162$ & 0.00 & $\mathrm{P}<0 / 001$ \\
Latency(ms) & $1.00 \pm 0.089$ & 0.00 & $\mathrm{P}<0 / 001$ \\
\hline
\end{tabular}

\section{Morphological study}

Estimation of the volume of anterior horn of spinal cord. After the sciatic nerve injury, the results showed a significant reduction in the total volume of anterior horn of spinal cord in axotomy group in comparison with the control group $(* \mathrm{P}<0.05)$ (Fig. 5A).

Estimation of the number of motor neurons. Our stereological analysis showed that the total number of the neurons of motor neurons was reduced in the axotomy group in comparison to the control group $(\mathrm{P}<0.05)$ (Fig. 5B).

\section{DISCUSSION}

This study showed that axotomy induced impairment in motor functional and histological structure of anterior horn of spinal cord. Crucially, we show that the tissue damage at the peripheral nerve is associated with the extent of
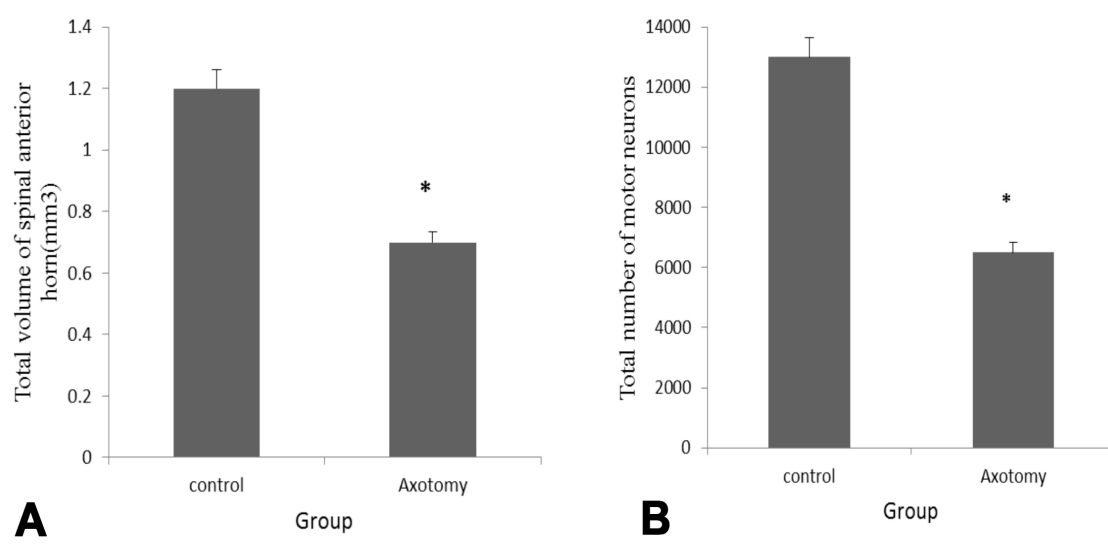

Fig. 5. Histological changes of spinal cord. (A) Statistical analysis of Total volume of anterior horn of spinal cord; (B) Statistical analysis of Total number of motor neurons. Data are expressed as mean $\pm \mathrm{SD}, * \mathrm{p}<0.05$ 
neurodegeneration at the anterior horn of spinal cord, which, in turn, is associated with clinically relevant impairment and neurophysiologic abnormalities. Axotomy has a very long experimental history as a paradigm to study the responses of motor neurons to injury (Nissl, 1892). In this study, The similar rates of death of motor neurons visualized with cresyl violet staining. The results showed that the disappearance of Nisslstained profiles from the ventral horn reflects death of these cells and is not caused by alterations in the staining properties of injured motor neurons. Our results have attributed a significant reduction in the total volume of the anterior horn of spinal cord in axotomy group when compared with the control group. The stereological analysis reveals a reduced number of the neurons of motor neurons in the axotomy group.

When a peripheral nerve is cut, there is an immediate paralysis of the muscles and loss of sensation in the area supplied by the nerve. Our findings also indicated timedependent decreases in SFI values due to sciatic nerve degeneration and gastrocnemius muscle atrophy in the axotomy groups compared to the control group. Compound action potential amplitude was significantly reduced in gastrocnemius muscle of axotomy group as compared to the control group. Furthermore, a significant difference was observed in the latency after sciatic nerve injury in both groups. These results are in partial agreement with finding of the death of motor neurons that showed with stereological analysis.

Many mechanisms may be involved in loss of anterior horn of spinal cord motor neurons. Soon after an axonal lesion, the process of Wallerian degeneration starts to occur in nerve fibers (Naidu \& David, 2009; Preyat et al., 2015).

In the distal stump, the cytoskeletal structures (neurofilaments and microtubules) go through disintegration, with accumulation of granular debris in the axoplasm. The cell membrane disappears, the axon undergoes fragmentation and the myelin rapidly disintegrates. In rodents, these events usually occur between 2 to 3 days following axotomy (Ma et al., 2013).There are also a number of changes at the nerve cell body level occurring after distal nerve trauma (Richardson et al., 2009).

The most consistent and conspicuous observation in cell body following nerve injury is probably chromatolysis, which involves the disintegration of the Nissl substance (large condensation of the endoplasmic reticulum). In addition, nuclear eccentricity, nucleolar enlargement and cell swelling can be clearly noted. Other changes include increases in cytoplasmic acid phosphatase and smooth endoplasmic reticulum with hypertrophy of Golgi apparatus. The highlight of the metabolic event seems to be an increase in the nuclear RNA synthesis, which is associated with an increase in cytoplasmic protein synthesis and content (Lieberman, 1971; Lieberman, 1974). A study by Martin et al, indicated that chromatolysis is the same as apoptosis. Their study showed that by 21 days following unilateral sciatic nerve avulsion in adult rats, the number of large motoneurons in the lumbar spinal cord was reduced by approximately $30 \%$ (Martin et al., 1999).

Other studies have also shown that ventral root avulsions cause motor neurons death associated with neuronophagia. As a model of retrograde degeneration, the L4-L5 ventral rhizotomy is similar to axotomy paradigms in the CNS, in which loss of differentiated transmitter phenotype (usually an early change) is accompanied by alterations in the neuronal cytoskeleton and, eventually, cell death (Gage et al., 1986; Koliatsos et al., 1989).

During the developmental cell death period, peripheral neurons are absolutely dependent on trophic factors produced by their targets, and those developing neurons that fail to compete successfully for sufficient target support die by apoptosis (Otten et al., 1979; Nakamura \& Myers, 2000).

\section{CONCLUSION}

Based on our finding presented herein, timedependent decreases in SFI values were determined in the axotomy groups. Compound action potential amplitude was markedly decreased in gastrocnemius muscle of axotomy group. On the other hand, a remarkable reduction in the total volume of the anterior horn of spinal cord was found in axotomy group. our findings have provided valuable data, but cannot lead us to completely understand the pathology of cells in the anterior horn of spinal cord after sciatic nerve injury.

RAOOFI, A.; GHARIBIAN, S. \& SADEGHI, Y. Inducción del deterioro por axotomía en la estructura motora funcional e histológica del asta anterior de la médula espinal. Int. J. Morphol., 37(3):11011106, 2019.

RESUMEN: En este estudio se examinaron los cambios motores en ratas sometidas a axotomía del nervio ciático. Las ratas se dividieron en dos grupos diez animales. El primer grupo (control) eran ratas sanas sin lesiones, y el grupo experimental consistió en ratas con nervio ciático lesionado sin tratamiento. A las 12 semanas, los segmentos de la médula espinal L4 y L5 fueron removidos. Se evaluó la función nerviosa mediante electromiografía muscular (EMG) y el índice de función ciática (IFC), simultáneamente con análisis histológicos de la médula espinal mediante métodos estereológicos. A las 12 semanas de la lesión nerviosa presentó déficit locomotor grueso. Además, se observó que el volumen del asta 
anterior y el número total de neuronas motoras disminuyeron después de la axotomía nerviosa $(\mathrm{P}<0,05)$. En conjunto, estos resultados indican que las lesiones de los nervios periféricos determinan graves consecuencias de la función motora de los miembros posteriores.

PALABRAS CLAVE: Degenerativa; Asta anterior; Estereología; Axotomía; Motor-funcional.

\section{REFERENCES}

Ahmadi, H.; Boroujeni, M. E.; Sadeghi, Y.; Abdollahifar, M. A.; Khodagholi, F.; Meftahi, G. H.; Hadipour, M.; Bayat, A. H.; Shaerzadeh, F. \& Aliaghaei, A. Sertoli cells avert neuroinflammation-induced cell death and improve motor function and striatal atrophy in rat model of Huntington disease. J. Mol. Neurosci., 65(1):1727, 2018.

Bain, J. R.; Mackinnon, S. E. \& Hunter, D. A. Functional evaluation of complete sciatic, peroneal, and posterior tibial nerve lesions in the rat. Plast. Reconstr. Surg., 83(1):129-38, 1989

Frade, J. M. \& Ovejero-Benito, M. C. Neuronal cell cycle: the neuron itself and its circumstances. Cell Cycle, 14(5):712-20, 2015.

Gage, F. H.; Wictorin, K.; Fischer, W.; Williams, L. R.; Varon, S. \& Bjorklund, A. Retrograde cell changes in medial septum and diagonal band following fimbriafornix transection: quantitative temporal analysis. Neuroscience, 19(1):241-55, 1986.

Grinsell, D. \& Keating, C. P. Peripheral nerve reconstruction after injury: a review of clinical and experimental therapies. BioMed Res. Int., 2014:698256, 2014.

Himes, B. T. \& Tessler, A. Death of some dorsal root ganglion neurons and plasticity of others following sciatic nerve section in adult and neonatal rats. J. Comp. Neurol., 284(2):215-30, 1989.

Hyun, J. K. \& Kim, H. W. Clinical and experimental advances in regeneration of spinal cord injury. J. Tissue Eng., 2010:650857, 2010.

Koliatsos, V. E.; Applegate, M. D.; Kitt, C. A.; Walker, L. C.; DeLong, M. R. \& Price, D. L. Aberrant phosphorylation of neurofilaments accompanies transmitter-related changes in rat septal neurons following transection of the fimbria-fornix. Brain Res., 482(2):205-18, 1989

Lieberman, A. R. Comments on the fine structural organization of the dorsal lateral geniculate nucleus of the mouse. Anat. Embryol. (Berl.), 145(3):261-7, 1974.

Lieberman, A. R. The axon reaction: a review of the principal features of perikaryal responses to axon injury. Int. Rev. Neurobiol., 14:49-124, 1971.

Martin, L. J.; Kaiser, A. \& Price, A. C. Motor neuron degeneration after sciatic nerve avulsion in adult rat evolves with oxidative stress and is apoptosis. J. Neurobiol., 40(2):185-201, 1999.

Naidu, M. \& David, P. Major cellular events in peripheral nerveregeneration: A brief overview. Int. Med. J., 8(1):69-72, 2009.

Nakamura, S. I. \& Myers, R. R. Injury to dorsal root ganglia alters innervation of spinal cord dorsal horn lamina involved in nociception. Spine (Phila Pa 1976), 25(5):537-42, 2000

Nissl, F. Uber die veränderungen der ganglienzellen am facialiskern des kaninchens nach ausreissung der nerven. Allg. Z. Psychiatr., 48:197-8, 1892.

Noorafshan, A.; Abdollahifar, M. A.; Asadi-Golshan, R.; Rashidian-Rashidabadi, A. \& Karbalay-Doust, S. Curcumin and sertraline prevent the reduction of the number of neurons and glial cells and the volume of rats' medial prefrontal cortex induced by stress. Acta Neurobiol. Exp. (Wars.), 74(1):44-53, 2014

Otten, U.; Goedert, M.; Schwab, M. \& Thibault, J. Immunization of adult rats against 2.5 S NGF: effects on the peripheral sympathetic nervous system. Brain Res., 176(1):79-90, 1979.

Park, K. K.; Liu, K.; Hu, Y.; Smith, P. D.; Wang, C.; Cai, B.; Xu, B.; Connolly, L.; Kramvis, I.; Sahin, M.; et al. Promoting axon regeneration in the adult CNS by modulation of the PTEN/mTOR pathway. Science, 322(5903):963-6, 2008.

Pierucci, A. \& de Oliveira, A. L. Increased sensory neuron apoptotic death 2 weeks after peripheral axotomy in C57BL/6J mice compared to A/J mice. Neurosci. Lett., 396(2):127-31, 2006.

Preyat, N.; Rossi, M.; Kers, J.; Chen, L.; Bertin, J.; Gough, P. J.; Le Moine, A.; Rongvaux, A.; Van Gool, F. \& Leo, O. Intracellular nicotinamide adenine dinucleotide promotes TNF-induced necroptosis in a sirtuin-dependent manner. Cell Death Differ., 23(1):29-40, 2015.
Richardson, P. M.; Miao, T.; Wu, D.; Zhang, Y.; Yeh, J. \& Bo, X. Responses of the nerve cell body to axotomy. Neurosurgery, 65(4 Suppl.):A74-9, 2009

Siemionow, M. \& Brzezicki, G. Chapter 8: Current techniques and concepts in peripheral nerve repair. Int. Rev. Neurobiol., 87:141-72, 2009.

Terenghi, G. Peripheral nerve regeneration and neurotrophic factors. J. Anat., 194(Pt. 1):1-14, 1999.

Vestergaard, S.; Tandrup, T. \& Jakobsen, J. Effect of permanent axotomy on number and volume of dorsal root ganglion cell bodies. J. Comp. Neurol., 388(2):307-12, 1997.

Wiberg, R.; Kingham, P. J. \& Novikova, L. N. A morphological and molecular characterization of the spinal cord after ventral root avulsion or distal peripheral nerve axotomy injuries in adult rats. J. Neurotrauma, 34(3):652-60, 2017.

Wood, M. D.; Kemp, S. W.; Weber, C.; Borschel, G. H. \& Gordon, T. Outcome measures of peripheral nerve regeneration. Ann. Anat., 193(4):321-33, 2011.

Zalewski, A. A. \& Gulati, A. K. Rejection of nerve allografts after cessation of immunosuppression with cyclosporin A. Transplantation, 31(1):88-9, 1981.

\author{
Corresponding author: \\ Yousef Sadeghi \\ Department of Biology and Anatomical Sciences \\ School of Medicine \\ Shahid Beheshti University of Medical Sciences \\ Tehran- IRAN
}

Email: dr.ysadeghi@yahoo.com

Received: 20-11-2018

Accepted: 01-03-2019 